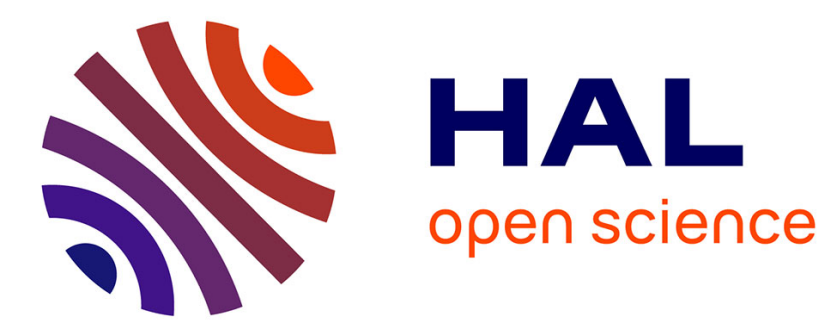

\title{
Microstrain analysis of titanium aluminides
}

\author{
Eva Héripré, Daniel Caldemaison, A. Roos, Jérôme Crépin
}

\section{To cite this version:}

Eva Héripré, Daniel Caldemaison, A. Roos, Jérôme Crépin. Microstrain analysis of titanium aluminides. Thermec 2009, Aug 2009, Berlin, Germany. pp.1330-1335, 10.4028/www.scientific.net/MSF.638-642.1330 . hal-00448325

HAL Id: hal-00448325

https://hal-mines-paristech.archives-ouvertes.fr/hal-00448325

Submitted on 19 Jan 2010

HAL is a multi-disciplinary open access archive for the deposit and dissemination of scientific research documents, whether they are published or not. The documents may come from teaching and research institutions in France or abroad, or from public or private research centers.
L'archive ouverte pluridisciplinaire HAL, est destinée au dépôt et à la diffusion de documents scientifiques de niveau recherche, publiés ou non, émanant des établissements d'enseignement et de recherche français ou étrangers, des laboratoires publics ou privés. 


\title{
Microstrain analysis of Titanium Aluminides
}

\author{
E. Hériprée ${ }^{2}$ D. Caldemaison ${ }^{2}$, A. Roos ${ }^{1}$, J. Crépin ${ }^{3}$ \\ ${ }^{1}$ DMSM/CEMN, ONERA, 29, avenue de la Division Leclerc, 92322 Châtillon Cedex, France \\ ${ }^{2}$ Laboratoire de Mécanique des Solides, CNRS UMR 7649 Ecole Polytechnique, 91128 Palaiseau \\ Cedex, France \\ ${ }^{3}$ MINES ParisTech, MAT- Centre des matériaux, CNRS UMR 7633, BP 8791003 Evry Cedex, \\ France
}

Corresponding author: heripre@Ims.polytechnique.fr (E. Héripré)

Keywords: digital image correlation, microextensometry, EBSD, polycrystal, TiAl

\begin{abstract}
The aeronautic and automotive industries have shown a renewed interest in TiAl based alloys. The main reasons for such an interest are their low density $\left(\sim 3,8 \mathrm{~g} / \mathrm{cm}^{3}\right)$, a good stiffness and a high strength for temperatures up to $750^{\circ} \mathrm{C}$. However, these alloys exhibit, in their polycrystalline form, a poor ductility at room temperature with widely scattered values. The aim of this study is therefore to characterise their mechanical behaviour with a multiscale methodology, coupling microstructure analysis and strain field measurements. This methodology employs orientation imaging microscopy as well as digital imaging correlation techniques with an intragranular step size of a few micrometers.

Two chemical compositions (47 at. $\% \mathrm{Al}$ and 48 at. \% $\mathrm{Al}$ ) and two processing routes (casting and powder metallurgy) are studied. Thus, four different types of final microstructures are considered, from fully lamellar $\mathrm{Ti}_{3} \mathrm{Al}\left(\alpha_{2}\right)+\operatorname{TiAl}(\gamma)$ microstructure to bimodal ones composed of two-phase $\left(\alpha_{2}+\gamma\right)$ lamellar grains and monolithic $\gamma$ grains. Firstly, the microstructure is characterised crystallographically and morphologically. This allows the identification of a representative volume element (RVE) inside the analysed volume. Then, uniaxial mechanical tests are performed for each microstructure, and the strain fields are analysed with a multiscale approach, which determines the spatial distribution of the strain field heterogeneity with respect to the different microstructures.
\end{abstract}

\section{Introduction}

The aim of this work concerns a better understanding of relationships between microstructures and mechanical properties of TiAl based alloys. In order to analyse these relationships quantatively, a multiscale methodology has been developed which couples microstructure analysis by EBSD to strain field measurements obtained by a digital imaging correlation technique (DIC) during mechanical tests.

\section{Experiments}

Materials. In this paper, four different rods of TiAl-based alloys are studied, with two different chemical compositions ( $\mathrm{Ti}-\mathrm{Al}_{47} \mathrm{Cr}_{2} \mathrm{Nb}_{2}$ and $\mathrm{Ti}-\mathrm{Al}_{48} \mathrm{Cr}_{2} \mathrm{Nb}_{2}$ ) and two different processing routes (casting and powder metallurgy). In the following, each material will be referenced by its percentage of aluminium content and its processing route, with PM denoting the powder metallurgy route and $\mathrm{C}$ the casting route: $47 \mathrm{PM}, 48 \mathrm{PM}, 47 \mathrm{C}$ and $48 \mathrm{C}$.

Each microstructure has been characterised by EBSD with a step size of the measurement of 1 $\mu \mathrm{m}$. Fig. 1 and 2 show the different microstructures for $\mathrm{Ti}-\mathrm{Al}_{47} \mathrm{Cr}_{2} \mathrm{Nb}_{2}$ and $\mathrm{Ti}-\mathrm{Al}_{48} \mathrm{Cr}_{2} \mathrm{Nb}_{2}$ respectively, for both processing routes. These areas are at least $400 \mu \mathrm{m} \times 400 \mu \mathrm{m}$, and each colour corresponds to a specific crystallographic orientation of the $\gamma$ phase, given by triplets of Euler angles. The $\alpha_{2}$ phases cannot be identified because the volume of the electronic probe of the conventional Tungsten filament SEM is larger than de grain size. The white areas in these figures 
correspond therefore to non-indexations of the measurement points and are considered as representing the small $\alpha_{2}$ phases. The grain boundaries between the $\gamma$ phases are determined from a local misorientation criterion, taken equal to $5^{\circ}$. Thus, the use of EBSD not only allows a 3D characterisation of the microstructures from a crystallographic point of view, as presented in Fig. 3, but it also allows a 2D morphological characterisation through a statistical analysis of the grain dimensions, as presented in Table 1.

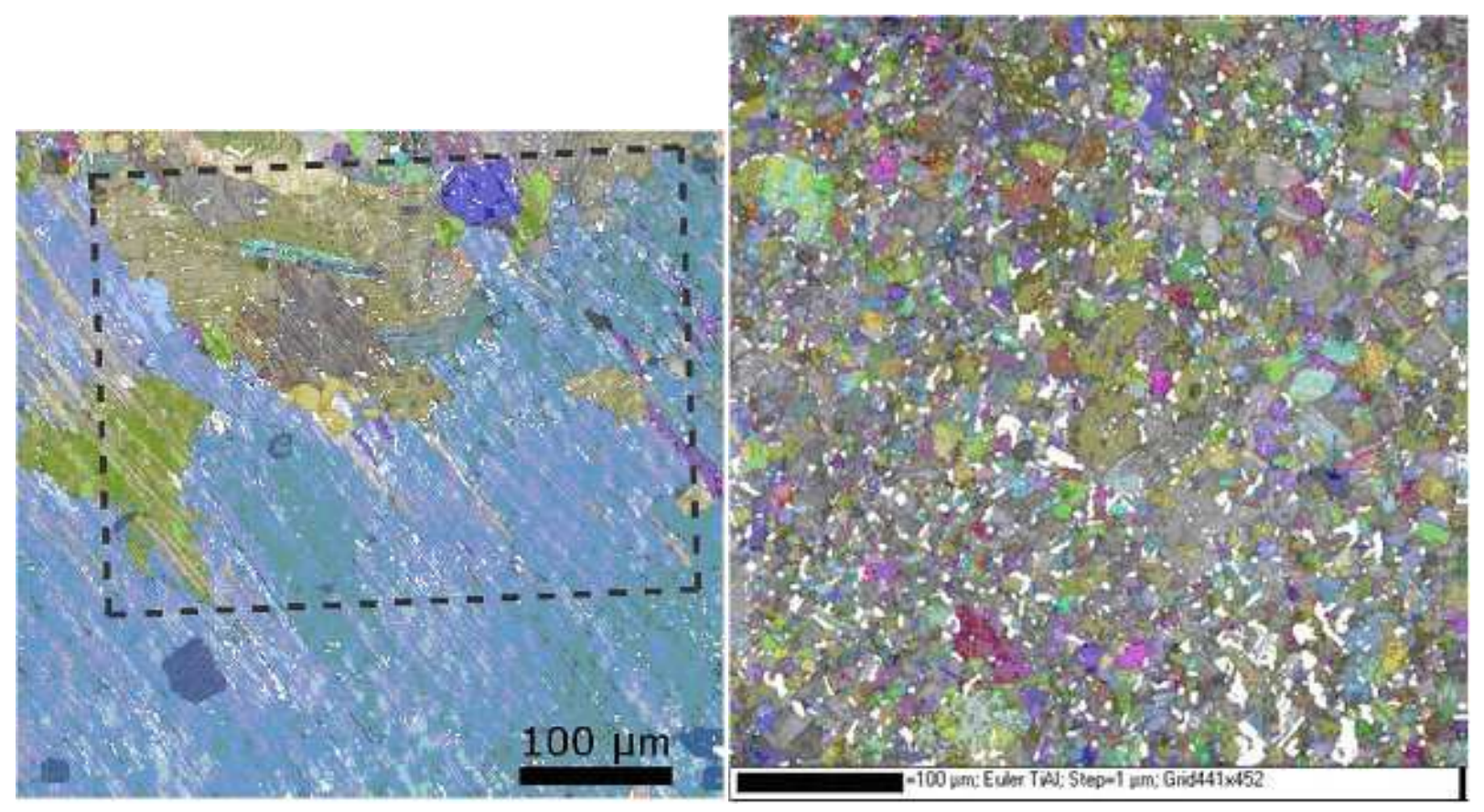

a)

b)

Figure 1: Orientation imaging microscopy of $\mathrm{Ti}^{-} \mathrm{Al}_{47} \mathrm{Cr}_{2} \mathrm{Nb}_{2}$. a) casting route. The dashed line represents the contour of the DIC imaging analysis area. b) powder metallurgy route.

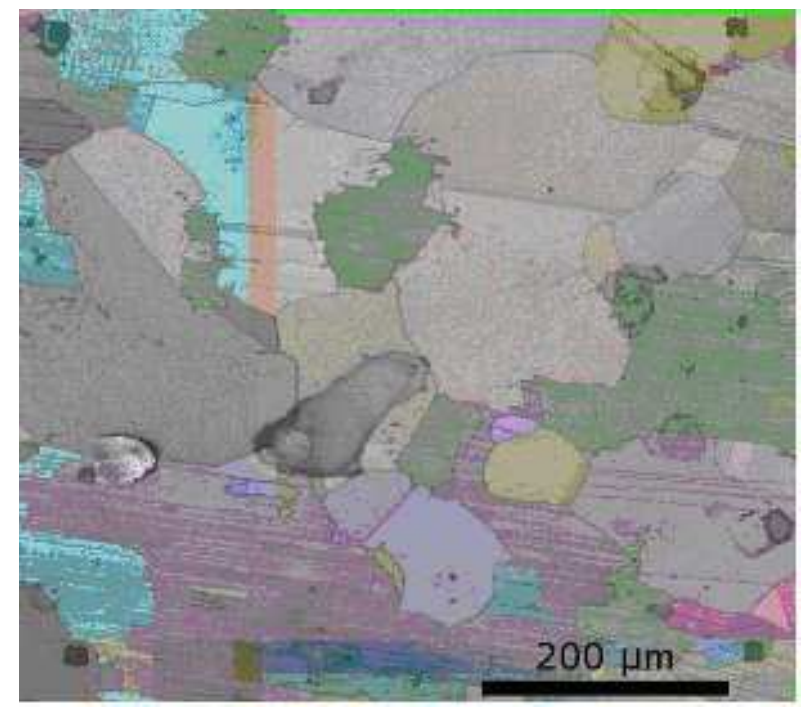

a)

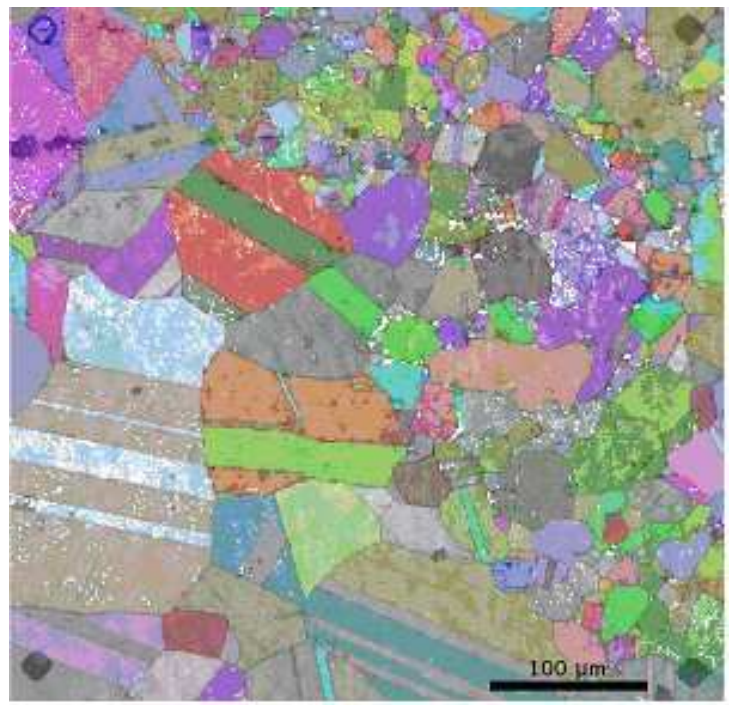

b)

Figure 2: Orientation imaging microscopy of $\mathrm{Ti}_{-} \mathrm{Al}_{48} \mathrm{Cr}_{2} \mathrm{Nb}_{2}$. a) casting route b) powder metallurgy route. 


\begin{tabular}{lcccc}
\hline Microstructure & $47 \mathrm{C}$ & $47 \mathrm{PM}$ & $48 \mathrm{C}$ & 48PM \\
\hline Average surface area $\left[\mu \mathrm{m}^{2}\right]$ & $>1000000$ & 45 & 1543 & 365 \\
Average equivalent grain size $[\mu \mathrm{m}]$ & $>564$ & 4 & 22 & 11 \\
Surface fraction of lamellar phase [\%] & 95 & 0 & 25 & 0 \\
Surface fraction of $\alpha_{2}$ phase $[\%]$ & 2 & 7 & 1 & 2 \\
\hline
\end{tabular}

Table 1: Statistical properties of the four microstructures.

From Fig. 3 and Table 1, it appears that the microstructure is far more sensitive to the processing route than to chemical composition. For instance, neither PM microstructure contains lamellar grains, but instead they have an equiaxed morphology with monolithic $\gamma$ grains containing crystallographic twins. Moreover, the crystallographic texture is quite isotropic for both cases. On the other hand, the "cast route" gives large $\left(\alpha_{2}+\gamma\right)$ lamellar grains with a much more anisotropic crystallographic texture, especially in the case of 47C. It appears that for the $47 \mathrm{C}$ microstructure, the huge size of the grains (> $500 \mu \mathrm{m}$ ) implies that the representative volume element (RVE) of the material cannot be contained within the dimensions of the sample, which are of the order of several millimeters. In this case, the macroscopic mechanical behaviour depends on the orientation of the lamellar grains with respect to the tensile or (compressive) axis, as was already observed by Umeda et al. [1].
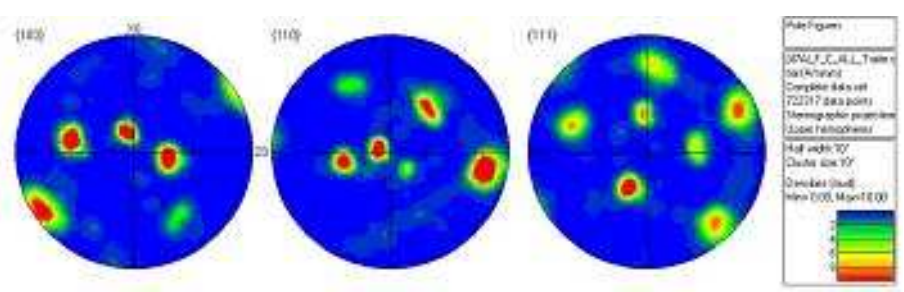

a)
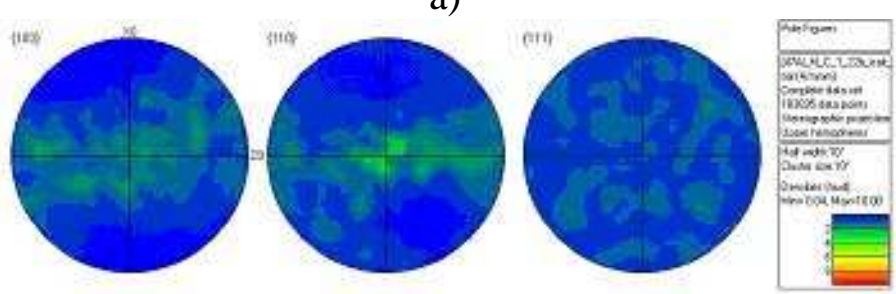

b)
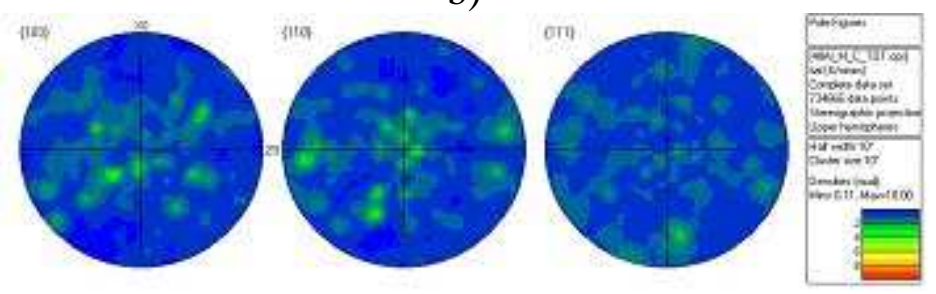

c)

Figure 3: Crystallographic texture associated with orientation imaging microscopy. a) fully lamellar microstructure of 47C, b) near $\gamma$ microstructure of 47PM, c) near $\gamma$ microstructure of 48PM. Each analysed surface area is $1 \mathrm{~mm}^{2}$.

Mechanical tests. Macroscopic mechanical tests have been carried out, coupled with a digital imaging correlation technique [2-5], allowing the observation of the local displacement and deformation fields directly linked to the underlying microstructures [6]. In this study, the local gauge length is taken equal to $2 \mu \mathrm{m}$, sufficiently small to be able to estimate the intragranular strain field. 


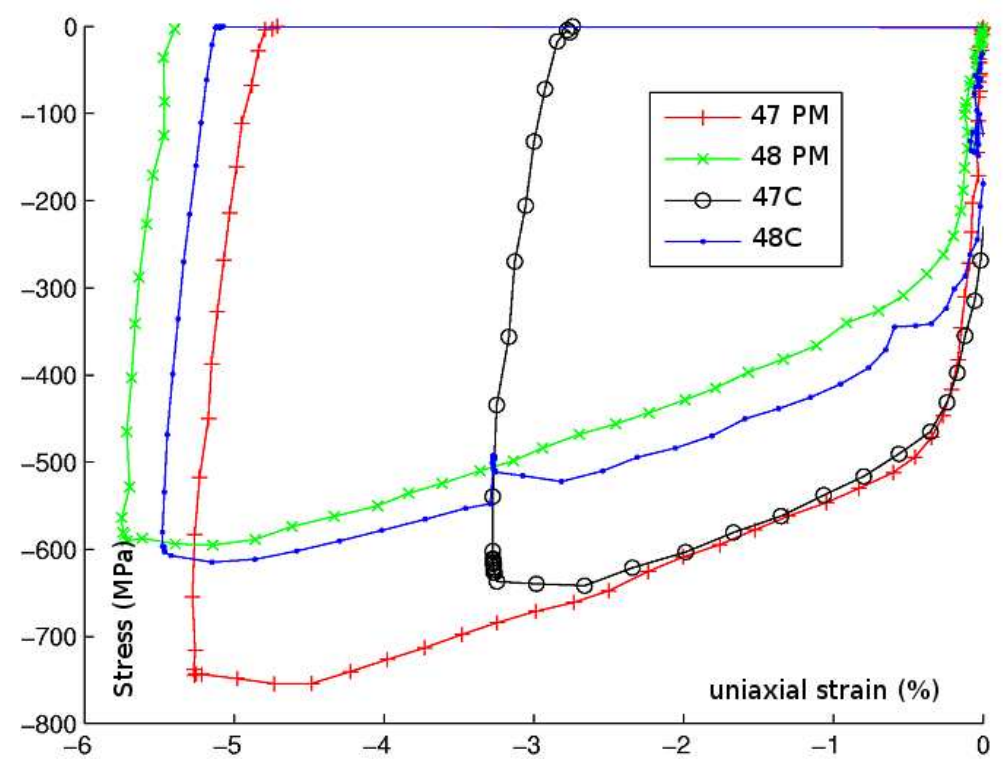

Figure 4: Macroscopic responses of the four specimens for uniaxial compressive tests.

Fig. 4 represents the macroscopic mechanical response of each sample for a compressive uniaxial test. The major discrepancy between the samples is observed for the yield stress with a stronger effect of chemical composition rather than of the processing route. Indeed, a greater mechanical yield stress is obtained for Ti- $\mathrm{Al}_{47} \mathrm{Cr}_{2} \mathrm{Nb}_{2}$, even though the lamellar grains are quite well oriented for easy glide $\left(45^{\circ}\right.$ with respect to the compressive axis). As for the strain hardening, all curves are parallel, meaning that the underlying deformation mechanisms should be the same for all the cases.

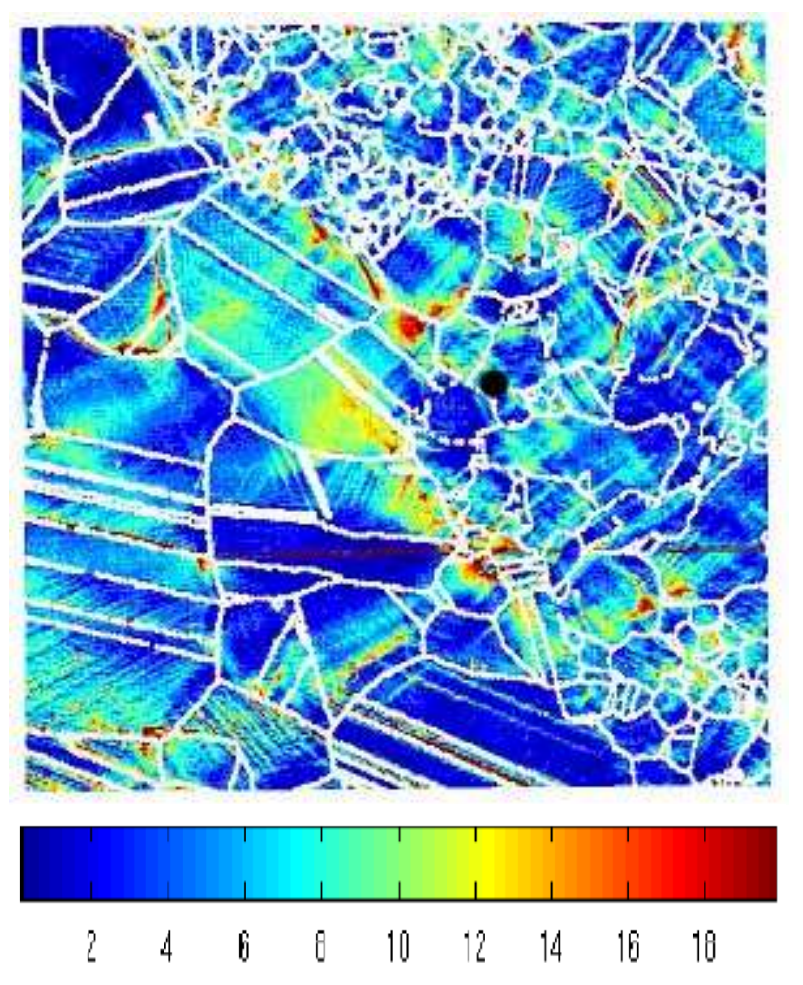

Figure 5: Superimposition of the Von Mises equivalent strain field with the microstructure for the 48PM material, for a macroscopic strain (vertical axis) of $-5.5 \%$ and a gauge length of $2 \mu \mathrm{m}$. The colour scale represents the magnitude of the strain [\%]. 
Locally, the question is now whether the deformation is homogeneously distributed or not, i.e. whether it follows a pattern directly linked to the microstructure, or not. Fig. 5 represents the superimposition of the local strain field with the corresponding microstructure shown previously in Fig. 2b. It can be observed that the strain is localised preferentially along the interfaces (grain boundaries) between small and large grains, but also along the twin boundaries inside the larger grains. Thus, the grain size heterogeneity of the monolithic $\gamma$ microstructure leads directly to a strain heterogeneity pattern.

In the case of the 47C microstructure, the strain path is directly linked to the orientation of the $\left(\alpha_{2}+\gamma\right)$ lamellar grains, as already proposed by Umeda [1] and as can be observed in Fig. 6a. For the 47PM microstructure (Fig. 6b), the strain is more homogeneously distributed inside the microstructure with no evident localisation linked with $\alpha_{2}$ grains.

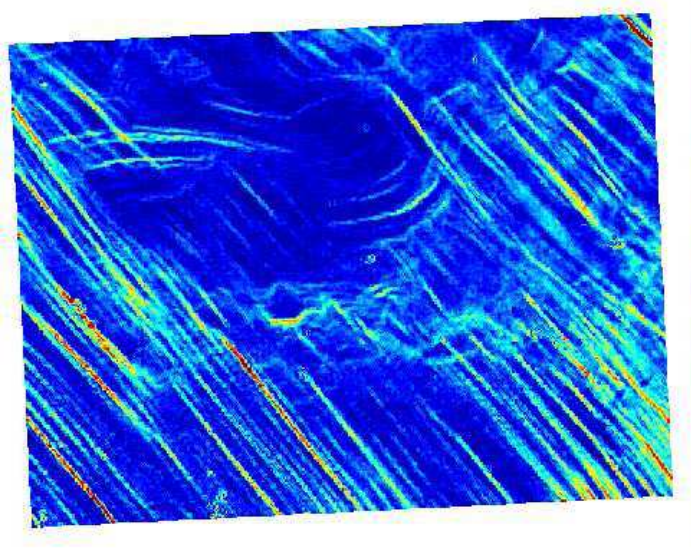

a)
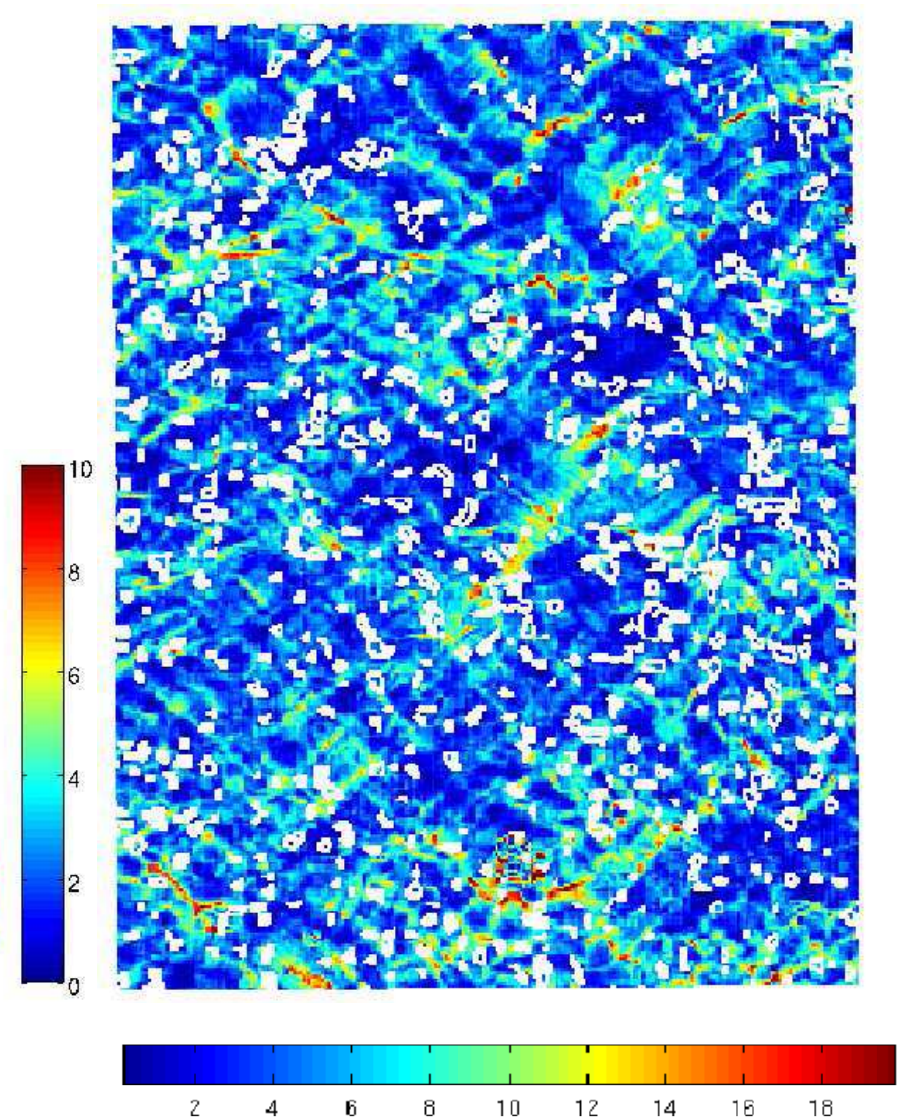

b)

Figure 6: a) Von Mises equivalent strain field localisation map for the $\mathrm{Ti}-\mathrm{Al}_{47} \mathrm{Cr}_{2} \mathrm{Nb}_{2}$ cast alloy corresponding to the dashed zone of Fig. 1a. The strain is localised along the lamellar interfaces, oriented preferentially at $45^{\circ}$ with respect to the compressive axis (vertical axis). The longitudinal macroscopic axial (i.e. in the vertical direction) residual strain is $-3 \%$ here. b) Von Mises equivalent strain field localisation map for the $\mathrm{Ti}-\mathrm{Al}_{47} \mathrm{Cr}_{2} \mathrm{Nb}_{2} \mathrm{PM}$ alloy. White spots correspond to the locations of the $\alpha_{2}$ phases. In this case the macroscopic residual axial strain is $-5 \%$.

\section{Conclusions}

Multiscale mechanical tests carried out on four different materials of two different chemical compositions and two different processing routes allow distinguishing between the effects due to the elaboration conditions and those due to the chemical composition. The latter is observed to constitute a first order parameter for the critical resolved shear stress and macroscopic yield stress. 
Furthermore, the morphology of the microstructure influences directly the localisation pattern of the deformation field. Thus, for the cast microstructures, well-oriented $\left(\alpha_{2}+\gamma\right)$ lamellar grains lead to severe strain localisation patterns. For the powder metallurgy microstructures, the same is observed for twin boundaries and strong heterogeneities of the grain size for monolithic $\gamma$ grains. These severe strain localisation patterns may be one of the main causes of the relatively poor ductility of these TiAl-based alloys.

\section{References}

[1] H. Umeda, K. Kishida, H. Inui, and M. Yamaguchi: Effects of Al-concentration and lamellar spacing on the room-temperature strength and ductility of PST crystals of TiAl. Mat. Sc. Eng. A239-240 (1997), pp 336-343.

[2] L. Allais, M. Bornert, T. Bretheau and D. Caldemaison: Experimental characterization of the local strain field in a heterogeneous elastoplastic material. Acta Metal. Mater. 42(11) (1994), pp 3865-3880.

[3] P. Doumalin: Microextensométrie par corrélation d'images. Ph.-D. thesis, Ecole Polytechnique, Palaiseau, France (2000).

[4] A. Tatschl and O. Kolednik: On the experimental characterization of crystal plasticity in polycrystals. Mat. Sc. Eng. A356 (2003), pp 447-463.

[5] B.M. Schroeter and D.L. McDowell: Measurement of deformation fields in polycrystalline OFHC copper. Int. J. Plast. 19 (2003), pp 1355-1376.

[6] E. Héripré, M. Dexet, J. Crépin, L. Gélébart, A. Roos, M. Bornert and D. Caldemaison: Coupling between Experimental Measurements and Polycrystal Finite Element Calculations for micromechanical study of metallic materials. Int. J. Plast. 23 (2007), pp 1512-1539. 